\title{
Predictors of nonunion and reoperation in patients with fractures of the tibia: an observational study
}

Katie Fong ${ }^{1}$, Victoria Truong ${ }^{1}$, Clary J Foote ${ }^{1}$, Brad Petrisor ${ }^{1}$, Dale Williams ${ }^{1}$, Bill Ristevski ${ }^{1}$, Sheila Sprague ${ }^{1,2}$ and Mohit Bhandari ${ }^{1,2^{*}}$

\begin{abstract}
Background: Tibial shaft fractures are the most common long bone fracture and are prone to complications such as nonunion requiring reoperations to promote fracture healing. We aimed to determine the fracture characteristics associated with tibial fracture nonunion, and their predictive value on the need for reoperation. We further aimed to evaluate the predictive value of a previously-developed prognostic index of three fracture characteristics on nonunion and reoperation rate.
\end{abstract}

Methods: We conducted an observational study and developed a risk factor list from previous literature and key informants in the field of orthopaedic surgery, as well as via a sample-to-redundancy strategy. We evaluated 22 potential risk factors for the development of tibial fracture nonunion in 200 tibial fractures. We also evaluated the predictive value of a previously-identified prognostic risk index on secondary intervention and/or reoperation rate. Two individuals independently extracted the data from 200 patient electronic medical records. An independent reviewer assessed the initial $x$-ray, the post-operative $x$-ray, and all available sequential $x$-rays. Regression and chi-square analysis was used to evaluate potential associations.

Results: In our cohort of patients, 37 (18.5\%) had a nonunion and 27 (13.5\%) underwent a reoperation. Patients with a nonunion were 97 times (95\% Cl 25.8-366.5) more likely to have a reoperation. Multivariable logistic regression revealed that fractures with less than $25 \%$ cortical continuity were predictive of nonunion (odds ratio $=$ 4.72; $p=0.02$ ). Such fractures also accounted for all of the reoperations identified in our sample. Furthermore, our data provided preliminary validation of a previous risk index predictive of reoperation that includes the presence of a fracture gap post-fixation, open fracture, and transverse fracture type as variables, with an aggregate of fracture gap and an open fracture yielding patients with the highest risk of developing a nonunion.

Conclusions: We identified a significant association between degree of cortical continuity and the development of a nonunion and risk for reoperation in tibial shaft fractures. In addition, our study supports the predictive value of a previous prognostic index, which inform discussion of prognosis following operative management of tibial fractures.

Keywords: Tibial shaft fractures, Reoperation, Secondary intervention, Fracture prognostic index, Fracture characteristics, Nonunion, Cortical continuity

\footnotetext{
* Correspondence: bhandam@mcmaster.ca

${ }^{1}$ Division of Orthopaedic Surgery, McMaster University, Hamilton, Canada

${ }^{2}$ Department of Clinical Epidemiology and Biostatistics, McMaster University, Hamilton, Canada
}

\section{Biomed Central}

(c) 2013 Fong et al.; licensee BioMed Central Ltd. This is an Open Access article distributed under the terms of the Creative Commons Attribution License (http://creativecommons.org/licenses/by/2.0), which permits unrestricted use, distribution, and reproduction in any medium, provided the original work is properly cited. 


\section{Background}

Tibial shaft fractures are the most commonly-occurring long bone fracture and are prone to a number of complications, many of which may require additional treatment in the form of secondary therapies or revision surgery to promote bony healing. Orthopaedic injuries represent $67 \%$ of injury admissions to Canadian hospitals [1]. Fractures and dislocations of the lower limb represent $38 \%$ of all injury admissions with a total of nearly 86,000 injury admissions due to fractures [1]. It is estimated that by 2020 , disability from traffic accidents (the major cause of fractures) will rank in the top three of all causes of disability [2].

Complications in fracture healing such as delayed union or nonunion occur in $4 \%$ to $48 \%$ of tibial shaft fractures, often resulting in the need for secondary intervention or additional treatment to stimulate bony union [3]. Reoperations are an example of such secondary intervention which can, and often does, result in a considerable impact in patient function and quality of life. Currently, there is much uncertainty with regards to what fracture characteristics predict fracture complications such as nonunion, particularly such cases which call for the need for secondary interventions in tibial shaft fracture patients [4]. Clinical and experimental studies have identified a number of potential factors that may help to predict such fracture complications [5-24]. However, these studies are often limited by single surgeon experiences, the use of outcome measures that are subject to variable interpretation, and limited rationale for the choice of prognostic variables. In addition, subsequent validation of previously developed prognostic indices for fracture healing is required [25].

Evidence is far from conclusive on what factors are predictive of fracture complications. To address these issues, we conducted a retrospective observational study among patients with operatively-managed fractures of the tibial shaft with the following key objectives: (1) to determine what fracture characteristics at the time of initial injury (baseline) are predictive of nonunion and the need for reoperation, (2) to provide preliminary validation of a previously-developed fracture prognostic index, and (3) to determine if certain aggregates of the variables included in the prognostic index have a higher predictive value for nonunion and reoperation compared to one another.

\section{Methods}

\section{Study methodology and procedures}

We conducted an observational study of 200 tibial shaft fractures to determine what fracture characteristics are predictive of a nonunion and the need for a reoperation. Medical records (clinical notes and radiographs) of patients with tibial shaft fractures were reviewed. This study was approved by the Research Ethics Board (project number 10-595-C under the Hamilton Health Sciences/McMaster Health Sciences, Research Ethics Board).

\section{Patient eligibility}

Consecutive patients with tibial shaft fractures were identified at three sites within a university-affiliated teaching hospital. Patients were identified through their hospital medical records by the Health Records Department. The study included patients who were treated for acute fractures and excluded those that were referred for a complication. In addition, patients were required to fulfill the following eligibility criteria: (1) 19 years of age or older, (2) tibial fracture requiring operative fixation with internal fixation, (3) sufficient clinical information available within the patient's medical record and (4) radiographs available for the assessment. Tibial fractures that extended into the joint, bilateral fractures and Gustilo-Anderson Type IIIc open fractures were excluded. Two individuals independently assessed each identified patient's electronic medical records to determine if they met the pre-defined eligibility for this study. Any disagreements were resolved by a third individual and reasons for exclusion were documented.

\section{Definitions}

Reoperation was defined as any invasive procedure completed to promote fracture healing. Such invasive measures included, but were not limited to, bone grafting, nail dynamization, or implant exchange. Nonunions were determined by the patient's attending physician as dictated in their clinical records and identified during the data collection process.

\section{Identification of prognostic variables}

Study specific case report forms were developed for this study. The case report forms were developed using previous literature and 15 surgeons in the field of orthopaedic trauma surgery. A sampling to redundancy strategy was utilized, by which additional experts were contacted until no new items were generated for the case report forms. A panel of experts rated their perceived importance of each identified factor on a scale of one to ten, with ten as the top priority to include in the analysis and one as the lowest priority to include in the analysis. The highest ranked factors were therefore included on the case report forms. The case report forms were piloted on ten sample patients before the study was initiated. The pilot test data was reviewed to confirm that the case report forms captured the information it was intending to collect. 


\section{Data collection}

Two individuals independently extracted the data from each patient's electronic medical record. The two individuals reviewed all available medical records including initial hospital notes from the emergency room consultation, the surgical consultation, the operative report(s), in-hospital progress reports, the hospital discharge summary, all fracture clinic notes, subsequent operative report(s) (if applicable), and all re-hospitalization notes (if applicable) related to the patient's included fracture. They recorded the data on the study-specific case report forms. Any disagreements were resolved by a third individual, who independently extracted the data in which there was a discrepancy.

\section{Radiographic evaluation}

An independent reviewer assessed the initial $x$-ray, the post-operative $\mathrm{x}$-ray, and all available sequential $\mathrm{x}$-rays. The independent reviewer assessed the radiographs and documented fracture characteristics, post-operative characteristics and any identified radiographic complications on the case report forms. Fracture characteristics included location of fracture, type of fracture, cortical continuity and bone loss. Post-operative characteristics included size of fracture gap and amount of cortical continuity (lack of bridging of tibial cortices), which were used as indicators of healing.

\section{Data management}

Data from both the available patient medical records and data from the case report forms completed during radiographic evaluation were consolidated and, in preparation for analysis, entered into a database and a subset of the data was reviewed. Reporting adverse events was not applicable, as the data sources used in this study did not contain physician attribution of causality of adverse events to any medicinal or surgical products.

\section{Sample size determination}

Our previous randomized trial in patients with tibial shaft fractures identified an event rate of a secondary intervention of $14 \%$ (95\% CI: $12-16 \%$ ) in closed fractures and $27 \%$ (95\% CI: 22-31\%) in open fractures [26]. Given a sample size of 200 patients with tibial shaft fractures treated operatively, we anticipated to have 50 patients (25\%) with one healing complication leading to an expected outcome event per predictor variable (EPV) of 10 for the logistic regression model. Based on simulation studies, EPV values of 10 (or greater) showed no major issues in terms of confidence interval coverage, type I error, relative bias and other model performance measures $[27,28]$.

\section{Statistical analysis}

Data was analyzed using SPSS Version 21.0 [SPSS, Chicago, IL]. Our primary analyses included looking at nonunions and reoperations.

Dichotomous data was reported as number of participants and proportions, with corresponding confidence intervals to estimate precision. Continuous data was presented as means and medians with standard deviations. Descriptive statistics describing the patients' demographics, fracture characteristics, fracture complications and management of the documented fracture complications were also provided.

The primary analysis was a multivariable logistic regression using the primary outcome (need for reoperation) as the dependent variable looking for predictor variables in patients with tibial shaft fractures at baseline. The same analysis was completed to assess fracture characteristics and their predictive value using nonunion as the secondary outcome.

We also conducted an exploratory regression analysis comparing different aggregates of two of the three fracture characteristics included in a previously-developed prognostic index for their predictive value using reoperation and nonunion as outcomes.

A chi-square test was performed to test the null hypothesis of no association between nonunion and reoperation.

\section{Results}

\section{Characteristics of the patients}

We identified 594 potentially eligible patients from the hospital database review. Of these, 200 were included in our analysis. Patients were excluded if they had an insufficient amount of follow-up clinical or radiographical data (141), a tibial fracture not fixed via operative internal fixation (108), a fracture extending into the joint (87), a non-tibial fracture (35), a bilateral fracture (17), or were under the age of 18 (6). The typical patient was a healthy male $(69.0 \%)$, averaging 42 years of age, who consumed alcohol (73\%), and had no previous injuries to the ipsilateral tibia (98\%) (Table 1). Most tibial fracture injuries were accompanied by injuries to the ipsilateral fibula (92\%). Of the fractures included, $43 \%$ were a result of a motor vehicle-related incident. Fracture injuries tended to be closed (78\%) and were treated with reamed intramedullary nailing (81\%). Post-operatively, patients did not suffer from any fracture complications during their hospital stay (97\%), which was often less than a week (Table 2).

\section{Nonunions and reoperations}

In our cohort of tibial fractures, 37 (18.5\%) went on to nonunion, as identified by the attending physician. Of the 37 patients with nonunion, $62.2 \%$ of them were 
Table 1 Characteristics of the patients

\begin{tabular}{|c|c|}
\hline Characteristic & No. (\%) of subjects \\
\hline Group sample size & $N=200$ \\
\hline \multicolumn{2}{|l|}{ Gender $(n=200)$} \\
\hline Male & $138(69.0)$ \\
\hline Female & $62(31.0)$ \\
\hline \multicolumn{2}{|l|}{ Age $(n=200)$} \\
\hline Mean age in years & $42 \pm 16.5$ \\
\hline \multicolumn{2}{|l|}{ Diabetes $(n=191)^{*}$} \\
\hline Type II (Insulin dependent diabetes) & $14 \times(7.3)$ \\
\hline Type I (Non-insulin dependent diabetes) & $10(5.2)$ \\
\hline No & $167(87.4)$ \\
\hline \multicolumn{2}{|l|}{ Tobacco use $(n=138)$} \\
\hline Yes & $64(45.7)$ \\
\hline No & $60(43.5)$ \\
\hline Previously used & $15(10.9)$ \\
\hline \multicolumn{2}{|l|}{ Health history $(n=189)$} \\
\hline None & $137(72.5)$ \\
\hline Vascular disease & $46(24.3)$ \\
\hline Myocardial Infarction and vascular disease & $3(1.6)$ \\
\hline Stroke and vascular disease & $2(1.1)$ \\
\hline Myocardial infarction & $1(0.5)$ \\
\hline \multicolumn{2}{|l|}{ Alcohol use $(n=95)$} \\
\hline Yes & $69(72.6)$ \\
\hline No & $26(27.4)$ \\
\hline \multicolumn{2}{|l|}{ Steroid use $(n=170)$} \\
\hline Yes & $14(8.2)$ \\
\hline No & $156(91.8)$ \\
\hline \multicolumn{2}{|l|}{ Previous injuries to the ipsilateral tibia $(n=183)$} \\
\hline Yes & $4(2.2)$ \\
\hline No & $179(97.8)$ \\
\hline
\end{tabular}

*n denominators do not equate to 200 due to missing values.

identified within the first six months of the initial injury. Additionally, 27 (13.5\%) of all included patients underwent a reoperation, with $55.6 \%$ of them occurring within the first six months of the initial injury.

\section{Factors associated with nonunion and reoperation}

Univariable analysis identified six fracture characteristics associated with the incidence of nonunion $(p<0.05)$, which included fractures with less than $25 \%$ cortical continuity (odds ratio $=6.44$ [95\% CI 1.89, 21.95]; $\mathrm{p}=0.003$ ), open fractures (odds ratio $=2.56[95 \% \mathrm{CI} 1.24,5.29] ; \mathrm{p}=0.011$ ), the presence of comminution (odds ratio $=2.21[95 \% \mathrm{CI}$ $1.05,4.66] ; \mathrm{p}=0.037$ ), and an oblique (odds ratio $=2.94$ [95\% CI 1.32, 6.58]; $\mathrm{p}=0.009$ ) or segmental (odds ratio = 3.17 [95\% CI 0.96, 10.46]; $\mathrm{p}=0.058$ ) fracture type (Table 3). Multivariable logistic regression analysis suggested that only
Table 2 Fracture characteristics

\begin{tabular}{|c|c|}
\hline Characteristic & No. (\%) of subjects \\
\hline \multicolumn{2}{|l|}{ Other injuries $(n=200)$} \\
\hline Yes & $183(91.5)$ \\
\hline No & $17(8.5)$ \\
\hline \multicolumn{2}{|l|}{ Side of injury $(n=200$ ) } \\
\hline Right & $112(56.3)$ \\
\hline Left & $87(43.7)$ \\
\hline \multicolumn{2}{|l|}{ Mechanism of injury $(n=197)^{*}$} \\
\hline Fall from standing & $43(21.8)$ \\
\hline Motor vehicle accident & $34(17.3)$ \\
\hline Twist & $26(13.2)$ \\
\hline Pedestrian motor vehicle accident & $22(11.2)$ \\
\hline Motorcycle accident & $19(9.6)$ \\
\hline Crush & $18(9.1)$ \\
\hline Recreational vehicle accident & $9(4.6)$ \\
\hline Fall from height & $8(4.1)$ \\
\hline Other & $18(9.1)$ \\
\hline \multicolumn{2}{|l|}{ Degree of soft tissue injury ( $n=165$ ) } \\
\hline Closed & $129(78.2)$ \\
\hline Open type 1 & $12(7.3)$ \\
\hline Open type 2 & $16(9.7)$ \\
\hline Open type 3A & $4(2.4)$ \\
\hline Open type 3B & $4(2.4)$ \\
\hline \multicolumn{2}{|l|}{ Method of fixation ( $n=193$ ) } \\
\hline Reamed IM nailing & $156(80.8)$ \\
\hline Plate fixation & $36(18.7)$ \\
\hline Unreamed IM nailing & $1(0.5)$ \\
\hline \multicolumn{2}{|c|}{ Post operative weightbearing status $(n=100)$} \\
\hline Nonweightbearing & $61(61.0)$ \\
\hline Partial weightbearing & $38(38.0)$ \\
\hline Full weightbearing & $1(1.0)$ \\
\hline \multicolumn{2}{|l|}{ Hospital stay post surgery $(n=199)$} \\
\hline Mean stay in days & $9.5 \pm 16.3$ \\
\hline \multicolumn{2}{|c|}{ Fracture complication during hospital stay $(n=144)$} \\
\hline No & $139(96.5)$ \\
\hline Yes & $5(3.5)$ \\
\hline
\end{tabular}

${ }^{*} \mathrm{n}$ denominators do not equate to 200 due to missing values.

cortical continuity remained predictive (odds ratio $=4.72$ [95\% CI 1.33, 16.76]; $\mathrm{p}=0.02$ ) (Table 4).

Alternatively, open fractures and transverse fractures were the only fracture characteristics that showed any significant predictive value for reoperation, as shown via univariable analysis (Table 5). All tibial fractures with less than $25 \%$ cortical continuity accounted for all 27 reoperations we identified in our sample. The presence of a transverse fracture was the only variable to approach 
Table 3 Univariable logistic regression model for predictors of nonunion

\begin{tabular}{|c|c|c|c|c|}
\hline Factor & Group sample size* & Nagelkerke R square & Odds ratio & \\
\hline$[95 \% \mathrm{Cl}]$ & Probability & & & \\
\hline Cortical Continuity & 193 & 0.108 & $6.444[1.892,21.950]$ & 0.003 \\
\hline \multicolumn{5}{|l|}{$50-100 \%$} \\
\hline \multicolumn{5}{|l|}{$0-25 \%$} \\
\hline Degree of Soft Tissue Injury & 199 & 0.520 & $2.561[1.238,5.295]$ & 0.011 \\
\hline \multicolumn{5}{|l|}{ Closed } \\
\hline \multicolumn{5}{|l|}{ Open } \\
\hline Comminution & 194 & 0.035 & $2.210[1.048,4.660]$ & 0.037 \\
\hline \multicolumn{5}{|l|}{ No } \\
\hline \multicolumn{5}{|l|}{ Yes } \\
\hline Transverse Fracture & 199 & 0.011 & $1.897[0.682,5.276]$ & 0.220 \\
\hline \multicolumn{5}{|l|}{ No } \\
\hline \multicolumn{5}{|l|}{ Yes } \\
\hline Oblique Fracture & 190 & 0.070 & $2.942[1.316,6.579]$ & 0.009 \\
\hline \multicolumn{5}{|l|}{ Transverse } \\
\hline \multicolumn{5}{|l|}{ Oblique } \\
\hline Segmental Fracture & & & $3.173[0.963,10.459]$ & 0.058 \\
\hline \multicolumn{5}{|l|}{ Transverse } \\
\hline Segmental & & & & \\
\hline
\end{tabular}

*n denominators do not equate to 200 due to missing values.

\begin{tabular}{|c|c|c|}
\hline Factor & Odds ratio $[95 \% \mathrm{Cl}]$ & Probability \\
\hline \multicolumn{3}{|l|}{ Group Sample Size ${ }^{*}=189$} \\
\hline \multicolumn{3}{|l|}{ Nagelkerke $R$ Square $=0.172$} \\
\hline Cortical Continuity & $4.716[1.327,16.761]$ & 0.017 \\
\hline \multicolumn{3}{|l|}{$50-100 \%$} \\
\hline \multicolumn{3}{|l|}{$0-25 \%$} \\
\hline Degree of Soft Tissue Injury & $1.262[0.533,2.985]$ & 0.597 \\
\hline \multicolumn{3}{|l|}{ Closed } \\
\hline \multicolumn{3}{|l|}{ Open } \\
\hline Comminution & $0.989[0.398,2.457]$ & 0.981 \\
\hline \multicolumn{3}{|l|}{ No } \\
\hline \multicolumn{3}{|l|}{ Yes } \\
\hline Oblique Fracture & $2.064[0.832,5.116]$ & 0.118 \\
\hline \multicolumn{3}{|l|}{ Transverse } \\
\hline \multicolumn{3}{|l|}{ Oblique } \\
\hline Segmental Fracture & $1.957[0.510,7.505]$ & 0.328 \\
\hline \multicolumn{3}{|l|}{ Transverse } \\
\hline Segmental & & \\
\hline
\end{tabular}

${ }^{*} n$ denominators do not equate to 200 due to missing values. significance for the incidence of reoperation in the multivariable logistic regression analysis (odds ratio $=3.03[95 \%$ CI 1.00, 9.18]; $\mathrm{p}=0.05$ ) (Table 6).

\section{Secondary treatment profile for nonunions}

Of the 37 nonunions reported in this study, $32.4 \%$ of them were treated with a noninvasive therapy option alone to promote bony union. Such options include, but are not limited to, ultrasound therapy, electrical stimulation, or medication. Additionally, $40.5 \%$ of the nonunions were treated with a reoperation alone and $24.3 \%$ were treated with a combination of both noninvasive therapies and a reoperation. There was only one case who did not receive any secondary treatment for nonunion.

\section{Validation of previous prognostic index for reoperation}

A previous index identified open fractures, presence of a fracture gap post-fixation, and a transverse fracture type as variables in a predictive model for reoperation within one year following operative management of tibial fractures [25].

Using the same prognostic risk model (Table 7), our findings largely confirmed the incremental increase in the risk of reoperation with one, two, and three prognostic risk factors. Patients with at least two of the three risk factors were more likely to develop a nonunion, with the presence of both a fracture gap and open 
Table 5 Univariable logistic regression model for predictors of reoperation

\begin{tabular}{|c|c|c|c|c|}
\hline Factor & Group sample size* & Nagelkerke R square & Odds ratio $[95 \% \mathrm{Cl}]$ & Probability \\
\hline Degree of Soft Tissue Injury & 199 & 0.065 & $3.094[1.347,7.109]$ & 0.008 \\
\hline \multicolumn{5}{|l|}{ Closed } \\
\hline \multicolumn{5}{|l|}{ Open } \\
\hline Comminution & 194 & 0.006 & $1.417[0.606,3.311]$ & 0.422 \\
\hline \multicolumn{5}{|l|}{ No } \\
\hline \multicolumn{5}{|l|}{ Yes } \\
\hline Transverse Fracture & 199 & 0.034 & $2.990[1.046,8.551]$ & 0.041 \\
\hline \multicolumn{5}{|l|}{ No } \\
\hline \multicolumn{5}{|l|}{ Yes } \\
\hline Oblique Fracture & & & $2.020[0.820,4.978]$ & 0.127 \\
\hline \multicolumn{5}{|l|}{ Transverse } \\
\hline \multicolumn{5}{|l|}{ Oblique } \\
\hline Segmental Fracture & 190 & 0.034 & $2.825[0.784,10.180]$ & 0.112 \\
\hline \multicolumn{5}{|l|}{ Transverse } \\
\hline Segmental & & & & \\
\hline
\end{tabular}

*n denominators do not equate to 200 due to missing values.

fracture having the highest predictive value for a nonunion over any other aggregate of two of the three variables included in the prognostic risk model (Table 8). Patients with at least two or all three risk factors were more likely to incur a reoperation. All possible aggregates of two of the three prognostic risk variables provided a predictive basis for reoperation (Table 9).

\section{Association between nonunions and reoperations}

Chi-square analysis found an association between nonunion and reoperation, $X^{2}(1, N=198)=101.4, p<$ 0.001. $12.1 \%$ of all included patients experienced both a nonunion and a reoperation and patients with a nonunion were 97 times (95\% CI 25.8-366.5) more likely to have a reoperation.

Table 6 Multivariable logistic regression model for predictors of reoperation

\begin{tabular}{|c|c|c|}
\hline Factor & Odds ratio $[95 \% \mathrm{Cl}]$ & Probability \\
\hline \multicolumn{3}{|l|}{ Group Sample Size ${ }^{*}=194$} \\
\hline \multicolumn{3}{|l|}{ Nagelkerke R Square $=0.152$} \\
\hline Degree of Soft Tissue Injury & $1.993[0.782,5.079]$ & 0.149 \\
\hline \multicolumn{3}{|l|}{ Closed } \\
\hline \multicolumn{3}{|l|}{ Open } \\
\hline Transverse Fracture & $3.027[0.998,9.178]$ & 0.050 \\
\hline \multicolumn{3}{|l|}{ No } \\
\hline Yes & & \\
\hline
\end{tabular}

${ }^{*} \mathrm{n}$ denominators do not equate to 200 due to missing values.

\section{Discussion}

\section{Key findings}

Our multivariate regression analysis further corroborates the well-supported concept that a lack of cortical continuity $(<25 \%)$ is a strong predictor of nonunion and reoperation $[6,11,25,29,30]$. Although the presence of an open fracture was not a significant covariate in the multiple logistic regression model, open fractures are known prognostic factors for complications following fracture fixation [31-35] and this characteristic demonstrated a significant association to the incidence of both nonunion and reoperation in the univariate models, suggesting a possible study power issue. Our findings suggest a trend towards increased reoperations with transverse fractures compared to oblique or spiral fractures and is consistent with previous reports of their characteristic association to high-impact injuries and the need for reoperation to achieve bony union in such cases [11,25].

Using our cohort of patients, we were able to independently evaluate the validity of a previous prognostic index. This index used three variables (open fracture,

Table 7 Risk of reoperation

\begin{tabular}{lcc}
\hline Condition & $\begin{array}{c}\text { Previous study } \\
(\mathbf{2 0 0 3})^{\mathbf{2 5}}\end{array}$ & $\begin{array}{c}\text { Current study } \\
\mathbf{( 2 0 1 3 )}\end{array}$ \\
\hline No Risk Factors* & $\mathrm{N}=192$ & $\mathrm{~N}=193$ \\
One Risk Factor & $3.8 \%$ & $0.0 \%$ \\
Two Risk Factors & $17.7 \%$ & $11.7 \%$ \\
Three Risk Factors & $47.0 \%$ & $23.7 \%$ \\
\hline
\end{tabular}

*Risk factors include: Fracture gap, Open fracture, Transverse fracture. 
Table 8 Logistic regression model for predictors of nonunion using a set and combination of three previouslyidentified prognostic variables

\begin{tabular}{lcccc}
\hline Factor & Group sample size* & Nagelkerke R square & Odds ratio [95\% Cl] & Probability \\
\hline One Risk Factor $^{ \pm}$ & 193 & 0.007 & $0.708[0.330,1.517]$ & 0.374 \\
Two Risk Factors & 193 & 0.045 & $2.450[1.165,5.154]$ & $3.800[0.967,14.938]$ \\
$\begin{array}{l}\text { Three Risk Factors } \\
\text { Combination of Two Risk Factors }\end{array}$ & 193 & 0.028 & 0.018 \\
$\quad$ Fracture Gap and Open Fracture & 193 & 0.056 & $3.382[1.601,7.143]$ \\
$\quad$ Fracture Gap and Transverse Fracture & 193 & 0.020 & $2.417[0.841,6.947]$ & 0.001 \\
$\quad$ Open Fracture and Transverse Fracture & 199 & 0.021 & $3.152[0.842,11.794]$ \\
\hline
\end{tabular}

*n denominators do not equate to 200 due to missing values.

${ }^{ \pm}$Risk factors include: Fracture gap, Open fracture, Transverse fracture.

presence of a fracture gap post-fixation, and transverse fracture type) and was developed using a cohort of 200 patients [25]. Using our study patients as a validation cohort, we are able to see the increase in reoperation rates in patients who satisfied the prognostic variable criterion, thereby confirming the predictive value of the risk index.

Logistic regression analysis using different aggregates of two of the three previously-developed prognostic risk variables indicated that a grouping of both a fracture gap and open fracture together was the only significant predictor for the incidence of nonunion. Using this observation to build upon the predictive value of the previously-identified risk index, such patients can be considered as having fractures of high risk for the development of nonunion and can therefore be more accurately identified to facilitate treatment options more appropriate for achieving bony healing.

It is of interest to note that although only a combination of a fracture gap and an open fracture was found to be significantly attributed to the incidence of nonunion alone, all combinations of the three previouslyidentified prognostic variables demonstrate predictive value for reoperation. The results indicate that although all included patients who experienced a reoperation had a tibial fracture with less than $25 \%$ cortical continuity, not all patients with a diagnosed nonunion, as determined by their attending physician, satisfied this same criterion. This observation leads us to believe that all reported reoperations in this study were performed in an effort to achieve bony union in a fracture showing little to no progression towards healing on its own [36]. There is potential evidence here that surgeons may be performing reoperations on fracture patients with the expectation of developing nonunion rather than the incidence of it. There is still a general consensus across the orthopaedic community that prognostic variables predicting fracture complications such as nonunion or delayed union remain poorly defined [4] and if nonunions are indeed being treated prematurely, further studies on the relationship between reoperations and the proceeding development of fracture union could be warranted based on these findings to truly determine the therapeutic effect of a reoperation and prevent unnecessary and potentially problematic secondary surgery for fracture patients.

In addition to the validation of a previously-developed prognostic risk index for reoperation, we have identified three important findings: (1) tibial fractures with less than $25 \%$ cortical continuity have the highest predictive value of nonunion and reoperation than any other fracture characteristic included in this study, (2) the

Table 9 Logistic regression model for predictors of reoperation using a set and combination of three previouslyidentified prognostic variables

\begin{tabular}{|c|c|c|c|c|}
\hline Factor & Group sample size* & Nagelkerke R square & Odds ratio $[95 \% \mathrm{Cl}]$ & Probability \\
\hline One Risk Factor ${ }^{ \pm}$ & 193 & 0.005 & $0.721[0.306,1.699]$ & 0.454 \\
\hline Two Risk Factors & 193 & 0.057 & $2.896[1.264,6.633]$ & 0.012 \\
\hline Three Risk Factors & 193 & 0.048 & $5.600[1.401,22.382]$ & 0.015 \\
\hline \multicolumn{5}{|l|}{ Combination of Two Risk Factors } \\
\hline Fracture Gap and Open Fracture & 193 & 0.106 & $4.294[1.847,9.984]$ & 0.001 \\
\hline Fracture Gap and Transverse Fracture & 193 & 0.045 & $3.667[1.244,10.806]$ & 0.018 \\
\hline Open Fracture and Transverse Fracture & 199 & 0.042 & $4.812[1.262,18.343]$ & 0.021 \\
\hline
\end{tabular}

${ }^{*} \mathrm{n}$ denominators do not equate to 200 due to missing values.

${ }^{ \pm}$Risk factors include: Fracture gap, Open fracture, Transverse fracture. 
combination of a fracture gap post-fixation and an open fracture yields patients that are at high risk for developing nonunion (3) orthopaedic surgeons may be prematurely treating patients with anticipated nonunion rather than the incidence of it via invasive surgical methods.

\section{Strengths and limitations}

Our findings are strengthened by (1) involving a number of experts during development of the case report forms and prognostic factor list; (2) using a comprehensive sampling of patients from three hospital sites within three university-affiliated academic centers; (3) including only patients with sufficient amount of follow-up data to identify healing or the occurrence of a bone healing complication; (4) choosing an outcome measure that is objective and of unequivocal importance to patients; (5) our thorough data collection and analytic methods, which included a compilation of data extracted from patient charts (completed independently by two reviewers) and separately from the radiographs.

The results have limitations, which include (1) our sample may not be completely representative of all tibial fracture patients, but only reflects those treated within three university affiliated academic centers; (2) the identified prognostic factors may only be generalizable to tibial fracture outcomes; (3) as a retrospective review, the data collected from patient charts may not always be reliable or complete; (4) our sample size may have been insufficient to definitively power our regression analyses.

\section{Conclusions}

The evidence from this study has identified a significant association between cortical continuity and both nonunions and the need for reoperation in tibial shaft fractures. In addition, our study reconfirmed the prognostic risk index proposed from an earlier study, which listed the presence of a fracture gap post-fixation, open fractures and transverse fracture types as risk factors for nonunion and reoperations in tibial shaft fractures. While severity of soft tissue injury and fracture type remain non-modifiable risk factors, cortical continuity, in many cases can be modified and better monitored via additional clinical assessment tools such as computed tomography (CT) supplementary and alternative to radiographic examination. Surgeon attention to technical aspects of the surgical procedure to obtain apposition of fracture ends and avoid gaps is paramount. Clinical assessment of the effectiveness of invasive surgery for achieving bony union can help determine if currently published prognostic risk factors for nonunion requiring reoperation are accurate, as our study provides evidence that surgeons may be performing additional surgery to treat the anticipation of nonunion development. Regardless, surgeons can use this information to guide discussions about patient prognosis following operative management of tibial fractures.

\section{Competing interests}

Funding for this research was provided by AMGEN Inc. Dr. Mohit Bhandari was funded, in part, by a Canada Research Chair.

\section{Authors' contributions}

Study Conception and Design: MB, SS. Acquisition of Data: MB, SS, KF, VT, CJF. Analysis and Interpretation of Data: MB, SS, KF. Drafting of the Manuscript: MB, SS, KF, VT. Critical Revision of the Manuscript: MB, CJF, BP, DW, BR, SS. Statistical Expertise: MB. Administrative, Technical, or Material Support: MB, SS. Study Supervision: MB, SS. All authors read and approved the final manuscript.

\section{Acknowledgements}

We are grateful to Simrit Bains for his help in the data extraction.

\section{Received: 13 July 2012 Accepted: 15 March 2013}

Published: 22 March 2013

\section{References}

1. Canadian Institute for Health information (ClHI): National Trauma Registry: Hospital Injury Admissions. Ottawa: Canadian Institute for Health Information; 2003.

2. Dormans JP, Fisher R, Pill S: Orthopaedics in the developing world: present and future concerns. J Am Acad Orthop Surg 2001, 9:189-196.

3. Bhandari M, Guyatt GH, Swiontkowski MF, Schemitsch E: Treatment of open tibial shaft fractures: a systematic overview and metanalysis. J Bone Joint Surg Br 2001, 83B:62-68.

4. Bhandari M, Guyatt GH, Tong D, Adili A, Shaughnessy SG: Reamed versus nonreamed intramedullary nailing of lower extremity long bone fractures: a systematic overview and meta-analysis. J Orthop Trauma 2000, 14:2-9.

5. Sarmiento A, Sharpe FE, Ebramzadeh E, Normand P, Shankwiler J: Factors influencing the outcome of closed tibial fractures treated with functional bracing. Clin Orthop 1995, 315:8-24.

6. Kyro A, Usenius JP, Aarnio M, Kunnamo I, Avikainen V: Are smokers a risk group for delayed healing of tibial shaft fractures? Ann Chir Gynaecol 1993, 82:254-262.

7. Giannoudis PV, MacDonald DA, Matthews SJ, Smith RM, Furlong AJ, De Boer $P$ : Nonunion of the femoral diaphysis: the influence of reaming and nonsteroidal anti-inflammatory drugs. J Bone Joint Surg Br 2000, 82:655-658.

8. Schmitz MA, Finnegan M, Natarajan R, Chainpine J: Effect of smoking on tibial shaft fracture healing. Clin Orthop 1999, 365:184-200.

9. Nyguist F, Berglund M, Nilsson BE, Obrant KJ: Nature and healing of tibial shaft fractures in alcohol abusers. Alcohol 1997, 32:91-95.

10. Pluhar GE, Heiner JP, Manley PA, Bogdanske JJ, Vanderby R Jr, Markel MD: Biomechanical evaluation of early fracture healing in normal and diabetic rats. J Orthop Res 2000, 18:126-132.

11. Oni OO, Dunning J, Mobbs RJ, Gregg PJ: Clinical factors and size of the external callus in tibial shaft fractures. Clin Orthop 1991, 273:278-283.

12. Sarmiento A: On the behavior of closed tibial fractures: clinical/ radiological correlations. J Orthop Trauma 2000, 14:199-205.

13. Tytherleigh-Strong GM, Keating JF, Court-Brown CM: Extraarticular fractures of the proximal tibial diaphysis: their epidemiology, management and outcome. J R Coll Surg Edinb 1997, 42:334-338.

14. Gaston P, Will E, Elton RA, McQueen MM, Court-Brown CM: Fractures of the tibia: can their outcome be predicted? J Bone Joint Surg Br 1999, 81:71-76.

15. Templeman DC, Gulli B, Tsukayama DT, Gustilo RB: Update on the management of open fractures of the tibial shaft. Clin Orthop 1998, 350:18-25.

16. Hogevold HE, Grogaard B, Reikeras O: Effect of short-term treatment with corticosteroids and indomethacin on bone healing: a mechanical study of osteotomies in rats. Acta Orthop Scand 1992, 63:607-611.

17. Engestaeter LB, Sudmann B, Sudmann E: Fracture healing in rats inhibited by locally administered indomethacin. Acta Orthop Scand 1992, 63:607-611.

18. Frymoyer JW: Fracture healing in rats treated with diphenylhydantoin (Dilantin). J Trauma 1976, 16:368-370. 
19. Huddleston PM, Steckelberg JM, Hanssen AD, Rouse MS, Bolander ME, Patel R: Ciprofloxacin inhibition of experimental fracture healing. J Bone Joint Surg Am 2000, 82:161-173.

20. Stinchfield F, Sankaran B, Samilson R: The effect of anticoagulant therapy on bone repair. J Bone Joint Surg Am 1956, 38:270-282.

21. Altman RD, Latta LL, Keer R, Renfree K. Hornicek FJ, Banovac K: Effect of non-steroidal anti-inflammatory drugs on fracture healing: a laboratory study in rats. J Orthop Trauma 1995, 9:392-400.

22. Cozen L: Does diabetes delayed fracture healing? Clin Orthop 1972, 82:134-140.

23. Dickson KF, Katzman S, Paiemont G: The importance of blood supply in the healing of tibial fractures. Contemp Orthop 1995, 30:489-493.

24. Dodds RA, Catterall A, Bitensky L, Chayen J: Effects on fracture healing of an antagonist of the vitamin K cycle. Calcif Tissue Int 1984, 36:233-238.

25. Bhandari M, Tornetta P III, Spraque S, Najibi S, Petrisor B, Griffith L, Guyatt GH: Predictors of reoperation following operative management of fractures of the tibial shaft. J Orthop Trauma 2003, 17:353-361.

26. S.P.R.I.N.T: Investigators: Randomized Trial of Reamed versus Non-Reamed Intramedullary Nailing of Tibial Shaft Fractures. J Bone Joint Surg Am 2008, 90(12):2567-2578

27. Peduzzi P, Concato J, Kemper E, Holford TR, Feinstein AR: A simulation study of the number of events per varable in logistic regression analysis. J Clin Epidemiol 1996, 49:1373-1379.

28. Vittinghoff $E$, McCulloch CE: Relaxing the rule of ten events per variable in logistic and Cox regression. J Clin Epidemiol 2006, 165:710-718.

29. Panjabi M, Walter S, Karuda M: Correlations of radiographic analysis of healing fractures with strength: a statistical analysis of experimental osteotomies. J Orthop Trauma 2000, 14:199-205.

30. Stegman P, Lorio M, Soriano R, Bone L: Management protocol for unreamed interlocking tibial nails for open tibial fractures. J Orthop Trauma 1995, 9:117-120.

31. Investigators FLOW: Fluid Lavage of Open Wounds (FLOW): Design and rationale for a large, multicentre collaborative $2 \times 3$ factorial trial of irrigating pressures and solutions in patient with open fractures. BMC Musculoskelet Disord 2010, 11:85.

32. S.P.R.IN.T Investigators: Study to prospectively evaluate reamed intramedullary nails in patients with tibial fractures (S.P.R.I.N.T.): Study rationale and design. BMC Musculoskelet Disord 2008, 9:91.

33. Jingushi S, Mizuno K, Matsushita T, Itoman M: Low-intensity pulsed ultrasound treatment for postoperative delayed union or nonunion of long bone fractures. J Orthop Sci 2007, 12:35-41.

34. Nicoll EA: Fractures of the tibial shaft: a survey of 705 cases. J Bone Joint Surg $\operatorname{Br} 1964,46(3): 373-387$

35. Gaebler C, Berger U, Schandelmaier P, Greitbauer M, Schauwecker HH, Applegate B, Zych G, Vecsei V: Rates and odds ratios for complications in closed and open tibial fractures treated with unreamed, small diameter tibial nails: a multicenter analysis of 467 cases. J Orthop Trauma 2001, 15:415-423.

36. S.P.R.IN.T Investigators: Prognostic Factors for Predicting Outcomes After Intramedullary Nailing of the Tibia. J Bone Joint Surg 2012, 94:1786-1793.

doi:10.1186/1471-2474-14-103

Cite this article as: Fong et al:: Predictors of nonunion and reoperation in patients with fractures of the tibia: an observational study. BMC Musculoskeletal Disorders 2013 14:103.

\section{Submit your next manuscript to BioMed Central and take full advantage of:}

- Convenient online submission

- Thorough peer review

- No space constraints or color figure charges

- Immediate publication on acceptance

- Inclusion in PubMed, CAS, Scopus and Google Scholar

- Research which is freely available for redistribution 